\title{
Acoustic similarity and response measures in STM
}

LOWELL D. GRONINGER and NANCY M. HENLEY, University of Maryland, Baltimore County, 5401 Wilkens Ave., Baltimore, Md. 21228

Ss were shown four lists of seven CVC words constructed with differing degrees of within-list acoustic similarity. Recall was measured both with and without regard to order. Degree of acoustic similarity did not affect ordered recall, but recall measured without regard to order was better for lists of greater similarity.

A problem central to an attempt to find consistency within short-term memory (STM) data is that of the unknown effects of different response measures and different degrees of acoustic similarity within materials that are used in STM studies. Evidence from long-term memory (LTM) studies such as that of Underwood, Runquist, \& Schulz (1959) indicates that the effect of semantic similarity of material depends on the response measure used. As items increase in semantic similarity, free recall is facilitated, while recall requiring the association or positioning of items is hindered. If the findings of Underwood et al with regard to semantic similarity in LTM may be applied to acoustic similarity in STM, a similar interaction would be expected between type of recall measure and acoustic similarity. Wickelgren (1965b) has found evidence in this direction. The present study is an attempt to reproduce Wickelgren's finding of an interaction, using a STM paradigm differing from that of Wickelgren and using word lists with a broader range of acoustic similarity than employed by Wickelgren.

\section{METHOD}

Four conditions related to degree of acoustic similarity were formed. The control (C) condition consisted of words with a minimum of common vowel and consonant sounds (tab, hog, yen, cam, nip, jut, sod). The words in the $A_{1}$ condition had identical vowel sounds with common consonant sounds minimized (dun, bum, tub, pup, cud, jug, rut), while the words in the $\mathbf{A}_{2}$ condition had both the first consonant and vowel in common (cop, cob, cot, cod, cog, cox, con). The words in the $\mathrm{A}_{2}{ }^{\prime}$ condition had the same degree of sound similarity as the words in the $A_{2}$

Fig. 1. Mean number correct for ordered recall (correct position) and derived free recall (correct response). condition, but the common consonant was at the end of the word, in rhyming position (lag, gag, nag, wag, jag, sag, tag). There were seven CVC words in each list, and all lists were equated for word frequency (Thorndike \& Lorge, 1944).

The Ss were 48 student volunteers from an introductory psychology course. All Ss served in all four conditions, with each of the 24 permutations of orders of the four conditions used twice. Four different random orders of words within lists were used; these were assigned at random to a particular order of presentation of conditions with the stipulation that all orders occur equally often.

A memory drum was used to present the items in a list at a $1-\mathrm{sec}$ rate, with the $S \mathrm{~s}$ required to say each item aloud. A $15-\mathrm{sec}$ recall period followed, in which the Ss were to write all of the items, in order if possible, that they could recall. The Ss were instructed not to write the last words first, but to start from the beginning of the list. Also, the Ss were told to guess at the list position of a word if they remembered the word but not its position. The recall period was made brief to discourage the generation of words from learned rules governing each list. There was a 35 -sec pause between presentation of the lists. Ss were told in advance that the words in some of the lists would sound alike, since pilot data showed that most Ss became aware of this while learning the lists. Five Ss were discarded who did not pronounce words consistently with the intent of the conditions.

\section{RESULTS}

The results were tabulated in terms of number correct and number and type of errors. Number correct was measured in two ways: by correct position (ordered recall), whereby an item had to be recalled in the same serial position in which it was presented, and by correct response (derived free recall), whereby the position in the list in which an item occurred was disregarded in scoring. Figure 1 shows the number correct in terms of the two response measures. A one-way analysis of variance with repeated measures was performed on the conditions within each response measure. The test of the correct-position data yielded a nonsignificant $F$ of 2.41 $(\mathrm{df}=3,141 ; \mathrm{p}>.05)$, while the test of the correct-response data was highly significant, with $F(3,141)=76.88$, $\mathrm{p}<.001$. Since all comparisons between conditions using the correct-response data are of interest, a Newman-Keuls test (Winer, 1962) for multiple comparisons was performed. Significance at the .01 level was shown for Conditions $C$ vs $A_{2}$, $C$ vs $A_{2}^{\prime}, \quad A_{1}$ vs $A_{2}, \quad A_{1}$ vs $A_{2}^{\prime}$, and $A_{2}$ vs $A_{2}{ }^{\prime}$. An additional comparison of interest is that involving the interaction between response measures and level of acoustic similarity. A two-way analysis of variance with repeated measures (using response measures and conditions as factors) showed this interaction to be significant $[F(3,141)=31.00, p<.001]$.

Table 1 shows intrusion errors divided into two categories: between-list (BL) errors (words that intruded from a previous list) and extra-experimental (EE) errors (words that intruded that were not

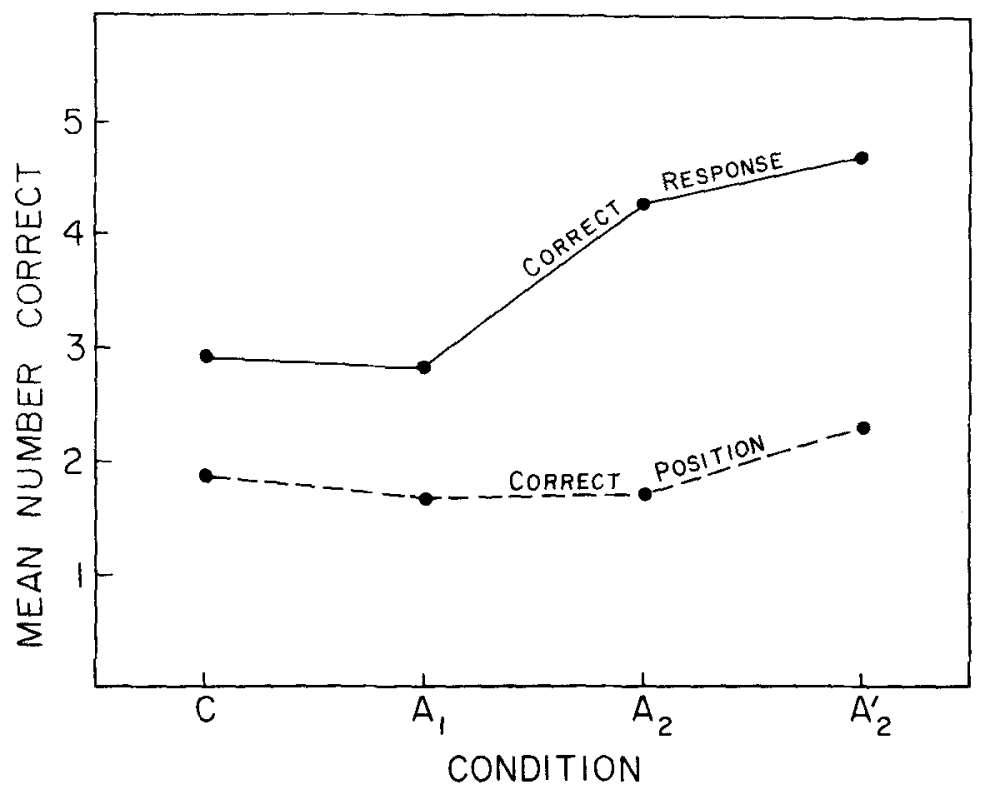


Table 1

Intrusion Errors by Type

\begin{tabular}{ccc}
\hline Condition & BL Errors & EE Errors \\
\hline $\mathrm{C}$ & 11 & 42 \\
$\mathrm{~A}_{1}$ & 4 & 44 \\
$\mathrm{~A}_{2}$, & 3 & 5 \\
$\mathrm{~A}_{2}$ & 1 & 3 \\
\hline
\end{tabular}

members of a previous list). It can be seen from this table that almost all the intrusion errors occurred in the $\mathrm{C}$ and $\mathrm{A}_{1}$ conditions, the conditions that had considerably lower free recall than the $\mathrm{A}_{2}$ and $\mathrm{A}_{2}{ }^{\prime}$ conditions. Another interesting aspect of the data not shown in Table 1 is that all EE errors had the same vowel sound as a word from the current list or one previously presented. The latter occurred despite the fact that $E E$ errors were quite evenly distributed with regard to order of presentation. Thus, the dominance of sound-alike errors was not an artifact of including vowel sounds from previous lists in the scoring. DISCUSSION

In general, the results seem consistent with Wickelgren's (1965b) predictions from a "phonemic-associative" model of STM and with studies concerning semantic similarity in LTM (Underwood et al, 1959). This agreement comes from the interaction between the response measures and the combined $\mathrm{A}_{2}$ and $\mathrm{A}_{2}{ }^{\prime}$ vs the combined $C$ and $A_{1}$ conditions. However, it should be pointed out that the effect of the $A_{1}$ condition did not conform to predictions based on the results of Wickelgren (1965b) and Underwood et al (1959). There was no increase in free recall in the $A_{1}$ condition compared to the $C$ condition and the difference between the response measures was not greater for the $\mathrm{A}_{1}$ condition compared to the $\mathrm{C}$ condition. In addition, the present results showed no decrease in ordered recall with increasing acoustic similarity as Wickelgren (1965b) found. However, the gross differences between the two studies in terms of response set familiarity and proactive inhibition might account for this since the magnitude of ordered recall in the present study was partially dependent on the magnitude of free recall, which was quite high in the high similarity conditions.

There are some other factors that complicate the interpretation of the results. While there can be no question that high acoustic similarity facilitates response learning as measured in the present study, it is not clear that the failure of the position-learning measure to increase proportionally to the free-recall measure is due solely to high acoustic similarity hindering the ordering of iterns. An additional explanation could be that ordering was more difficult because more words were recalled that had to be ordered. Also, the present study did not separate acoustic similarity from formal (i.e., graphic) similarity since this was not possible while controlling word length, frequency, and phonetic structure within and between the seven-item lists. However, from the results of Baddeley (1966), who found no significant effect for formal similarity in his STM study, it would appear that formal similarity is not a powerful factor.

The large differences in the effects of response learning and position learning across the acoustic dimension point out a problem in STM studies. Many studies, such as those of Baddeley (1966), Dale \& McGlaughlin (1968), and Groninger (1969), have used only one level of acoustic similarity. Since acoustic effects can vary with the degree of acoustic similarity, particularly if response learning is involved, studies using different degrees of similarity could get different results for this reason alone.

It should also be noted that while all EE errors shared a common vowel with a word from one of the experimental lists, which would be expected from the work of
Conrad (1964) and Wickelgren (1965a), the number of EE errors did not increase with high degrees of acoustic similarity. However, since there were fewer words that fit the list construction rules for the high-similarity lists, fewer EE errors might be expected there.

The difference between the $\mathrm{A}_{2}$ and $\mathrm{A}_{2}{ }^{\prime}$ conditions with the unordered recall measure is difficult to explain on a theoretical basis, since the two lists were designed to be equal in amount of acoustic similarity. It is possible that cultural emphasis on rhyming (e.g., in poetry and slang) could serve both to call attention to word-end similarities and to facilitate manipulation of rhymed words.

\section{REFERENCES}

BADDELEY, A. D. Short-term memory for word sequences as a function of acoustic, semantic and formal similarity. Quarterly Journal of Experimental Psychology, 1966, 18, 362-365.

CONRAD, R. Acoustic confusions in immediate memory. British Journal of Psychology, 1964, 55, 75-84.

DALE, H. C. A., \& McGLAUGHLIN, A. Acoustic similarity and retroactive inhibition in paired associates. Psychonomic Science, 1968, 13, 225-226.

GRONINGER, L. D. A test of the distinction between short-term memory and long-term memory. Unpublished doctoral dissertation, University of Illinois, 1969.

THORNDIKE, E. L., \& LORGE, I. The teacher's word book of 30,000 words. New York: Bureau of Publications, Teachers College, Columbia University, 1944.

UNDERWOOD, B. J., RUNQUIST, W. A., \& SCHULZ, R. W. Response learning in paired-associate lists as a function of intralist similarity. Journal of Experimental Psychology, 1959, 58, 70-78.

WICKELGREN, W. A. Acoustic similarity and intrusion errors in short-term memory. Journal of Experimental Psychology, 1965a, 70, 102-108.

WICKELGREN, W. A. Short-term memory for phonemically similar lists. American Journal of Psychology, 1965b, 78, 567-574.

WINER, B. J. Statistical principles in experimental design. New York: McGraw-Hill, 1962. 